\title{
Los agentes contralores y la gestión de inversiones en las universidades públicas del Perú: percepción de los directivos universitarios
}

\section{Controllers and investment management in peruvian public universities: perceptions of university managers}

\author{
Raymundo Arnao Rondán ${ }^{1}$ \\ ${ }^{1}$ Facultad de Ingeniería Económica, Estadística y Ciencias Sociales, Universidad Nacional de Ingeniería, \\ Lima, Perú \\ *E-mail: rarnaor@uni.edu.pe \\ Recibido (Received): 23/06/2020 Aceptado (Accepted): 07/10/2020 Publicado (Published): 15/12/2020
}

\begin{abstract}
RESUMEN
En Perú, las universidades públicas tienen dificultades para ejecutar sus proyectos de inversión. En el periodo 2016-2019, el conjunto de ellas ha tenido una baja ejecución algo ascendente, entre $44 \%$ y $69 \%$, postergando la atención de necesidades insatisfechas importantes en formación académica, investigación, entre otras.

La presente investigación parte de la idea avalada por la teoría y la evidencia empírica: que la percepción es un importante factor en la toma de decisión y en la baja ejecución de inversiones en las universidades públicas. Su objetivo general es conocer si el sistema de control -a través de los agentes contralores- influye negativamente o no en la toma de decisión de los directivos de las universidades públicas directamente involucradas en la gestión de inversiones.

Para su desarrollo, se revisó la normatividad que rige el sistema de control en el Perú, así como la que concierne a la gestión de inversiones. Seguidamente, se revisó la literatura pertinente, para luego con ambos insumos diseñar una encuesta que se aplicó a los antes mencionados directivos. El procesamiento de los datos recopilados mediante la encuesta proveyó información importante para determinar en qué modo la percepción del directivo respecto de la actuación de los agentes contralores, constituye un factor que dificulta o no su desempeño. $Y$ sobre la base del respectivo análisis, se extrajo conclusiones y formuló recomendaciones, con el fin de coadyuvar en la mejor gestión de inversión en las universidades públicas para atender relevantes demandas en formación académica, investigación y otras del ámbito universitario público nacional.
\end{abstract}

Palabras Clave: Agente Contralor, Universidad Pública, Inversión, Directivo, Percepción, Gestión, Encuesta.

\begin{abstract}
In Peru, public universities have difficulties in executing their investment projects. In the period 2016-2019, all of them have had a low and somewhat increasing execution, between $44 \%$ and $69 \%$; postponing the attention of important unsatisfied needs in academic training, research, among others.
\end{abstract}

This research is based on the idea supported by theory and empirical evidence: that perception is an important factor in decision-making; and, the low execution of investments in public 
universities. Its general objective is to find out whether or not the control system - through the control agents - has a negative influence on the decision-making of public university managers directly involved in investment management.

For its development, the regulations governing the control system in Peru were reviewed, as well as those concerning investment management. Next, the relevant literature was reviewed, and then a survey was designed and applied to the aforementioned managers. The processing of the data collected through the survey provided important information to determine in what way the manager's perception of the performance of the controlling agents constitutes a factor that hinder or not their performance. Based on the respective analysis, conclusions were drawn and recommendations were formulated to help improve investment management in public universities in order to meet the relevant demands in academic training, research and other areas of the national public university sector.

Keywords: Controlling Agent, Public University, Investment, Manager, Perception, Management, Survey.

\section{INTRODUCCIÓN}

\subsection{El problema y el tema de investigación}

Si bien desde hace muchos años es una verdad de perogrullo la dificultad que tiene el sector público del país en ejecutar adecuada y oportunamente su presupuesto de inversiones, esa dificultad se acentúa en situaciones de fenómenos naturales u otras emergencias (Fenómeno Niño Costero en diciembre de 2016 - mayo de 2017, COVID-19, etc.).

Las universidades públicas no son ajenas a esa incómoda realidad; por ejemplo, tienen dificultades para ejecutar sus proyectos de inversión. Según el Portal Transparencia Económica del Ministerio de Economía y Finanzas (MEF), el conjunto de ellas ha tenido los siguientes niveles de ejecución en cuatro recientes años: $43,5 \%$ en el $2016 ; 61,7 \%$ en el 2017; 63,8\% en el 2018; y 69,4\% en el 2019; que refleja una considerable diferencia entre lo programado y lo que finalmente se ejecuta. Y la no concreción oportuna de las inversiones implica que la formación académica y la investigación -entre otras- en la universidad pública sufra la postergación de atención de necesidades insatisfechas importantes.

La descripción sobre las mencionadas dificultades e insatisfacciones en la relación sector público y habitante peruano abunda; pero se carece de una adecuada identificación y descripción de los factores que determinan la deficiente actuación de la administración pública en situaciones normales, y de aquellos que no permiten resolver las situaciones de urgencia o emergencia que se le presenta. Este tipo de limitaciones alcanza también a la gestión de las inversiones públicas en el país.

Nuestra administración pública está inmersa en un entorno complicado. Está regida por normas y constituida por servidores (trabajadores) públicos, cuyas principales 
responsabilidades recaen sobre sus más importantes directivos. Estos a su vez tienen capacidades (condiciones cognitivas, afectivas y psicomotrices fundamentales para aprender y denotan la dedicación a una tarea), destrezas (habilidades motoras requeridas para realizar ciertas actividades con precisión) y habilidades (procesos mediante los cuales se realizan tareas y actividades con eficacia y eficiencia), los cuales se ponen en ejercicio en un entorno de engorrosos trámites, intereses políticos, riesgos de corrupción, la presión de la prensa, la demanda de la población con necesidades insatisfechas y la participación del Sistema Nacional de Control, a través de sus agentes contralores.

En la mencionada situación, el directivo público tiene una percepción de su entorno -que se podría denominar "medio ambiente laboral de su intervención"-, que determina que actúe de cierta manera en el ejercicio de su función y, en el caso específico que corresponde, incide en su modo de actuar en la gestión de la inversión pública a su cargo.

Lo señalado es amplio, complejo y poco estudiado en nuestro país y a nivel de Latinoamérica. Ante ello, el presente estudio se circunscribe al caso de la gestión de inversiones en las universidades públicas del Perú. Siendo, empero, también este tema amplio, el estudio se enfoca en el importante papel que ejercen los agentes contralores del Sistema Nacional de Control en la percepción de los directivos que tiene a cargo ese tipo de gestión. En tal sentido, esta investigación se orienta a identificar las características de esa percepción, sobre la base de una encuesta estructurada en función de las normas que rigen al Sistema Nacional de Control y a la Contraloría General de la República (CGR), que deben tener en cuenta los agentes contralores.

El Sistema Nacional de Control indica que las tareas de control interno en el sector público corresponden, por un lado, al equipo profesional de los órganos de control institucional establecidos en las entidades públicas y al de la CGR; por otro, a los directivos de las entidades públicas. $Y$ atendiendo a los propósitos de la presente investigación, es necesario diferenciarlos adecuadamente, por consiguiente, se va a denominar en este documento a los que dependen funcionalmente de la CGR (los dos primeros), agentes contralores.

\subsection{Síntesis del marco teórico}

En cuanto al marco teórico que concierne a los agentes contralores, se puede citar la investigación publicada por el BID (Jarquin et al., 2018). En ella se aplica la siguiente definición de la Organización Internacional de las Entidades Fiscalizadoras Superiores (INTOSAI), respecto de lo que se entiende por Auditoría de Desempeño: "es una revisión independiente, objetiva y confiable sobre si las acciones, sistemas, operaciones, programas, actividades y organizaciones del Gobierno operan de acuerdo con los principios de economía, eficiencia y eficacia, y sobre si existen áreas de mejora" (Jarquin et al., 2018, p. 
xiii). Sobre la base de una encuesta dirigida a las Entidades Fiscalizadoras Superiores ${ }^{8}$ (EFS) de 23 países de la región, se propone evaluar el estado de avance de la Auditoría de Desempeño en América Latina y el Caribe a diciembre de 2015; y, desde una aproximación descriptiva, el documento destaca el alcance y progreso heterogéneo en la materia, así como algunas oportunidades y desafíos para su posicionamiento como herramienta de mejora de la gestión pública (Jarquin et al., 2018).

Jarquin et al. (2018) refieren, entre sus conclusiones, que: i) la auditoría de desempeño es efectivamente una de las áreas más importantes de la evolución de las EFS en América Latina y el Caribe; ii) el desarrollo de la auditoría de desempeño en la región, con diferentes niveles de avance, vienen asumiendo las mejores prácticas identificadas en países con mayor trayectoria en la materia; iii) en la mayoría de los países analizados para este estudio, existe una limitada medición y divulgación de los costos y beneficios de la auditoría de desempeño, con el riesgo de perder legitimidad al no poder explicar el valor agregado del esfuerzo de las EFS; iv) existe limitado apoyo de los actores clave (responsables de los programas de gobierno a auditar, los legisladores y los ciudadanos) para garantizar el objetivo de la auditoría de desempeño de mejorar el programa de gobierno auditado.

Adicionalmente, el referido documento de Jarquin et al. (2018) identifica como causa importante de que algunas instituciones no realizan auditoría de desempeño, a la predominante falta de personal calificado en ellas.

El documento de Jarquin et al. (2018) presenta una interesante investigación desde el punto de vista de lo que manifiestan las propias EFS de América Latina y el Caribe, entes rectores de la auditoría de la gestión pública en sus respectivos países; pero está ausente el análisis de lo que entienden y piensan acerca de la auditoría de desempeño los agentes a cargo de los programas de gobierno a auditar, los legisladores y los ciudadanos. Quizá en la interacción de los dos grupos de involucrados (auditores y auditados) en el proceso de la auditoría de desempeño, existe una brecha de lo que cada uno percibe de lo que debe ser su propia actuación y la que debe ser del otro. Y posiblemente esta brecha podría proporcionar importante explicación sobre lo que el propio documento identifica como "limitado apoyo de los actores clave para garantizar el objetivo de la AD [auditoría de desempeño] de mejorar el programa de gobierno auditado" (Jarquin et al., 2018, p. xiv).

Considerando la referida investigación, así como los antecedentes expuestos en el presente documento respecto de la CGR y los agentes contralores del sistema de control del país, se infiere la importancia -y quizá urgencia- de un buen diseño y aplicación de la auditoría de desempeño en Perú.

\footnotetext{
${ }^{8}$ Son entidades equivalentes a la que en el Perú es la Contraloría General de la República.
} 
Por otra parte, la inconveniencia del excesivo celo en el control de procedimientos en las acciones del Estado, así como de la relación de la asimetría de la información y la corrupción, cuyo incremento a su vez induce ese mayor control, son objeto de estudio por el Premio Nobel de Economía 2001, Joseph Stiglitz.

Stiglitz $\left(2002^{9}\right)$ analiza detalladamente con los respectivos soportes teóricos y evidencia empírica, que dependiendo de determinados factores y las condiciones específicas del caso -entre estos destaca las imperfecciones de la información-, el sector público demuestra ser más eficiente que el sector privado, y en otros, que se presenta la situación contraria. De manera que prueba que no es verdad absoluta que en toda actividad económica la iniciativa privada es mejor que la intervención del Estado.

De manera particular, acerca de la corrupción, Stiglitz (2002) afirma:

El problema de la corrupción también puede ser apreciado desde la perspectiva teórica de la información. Si existiese una información perfecta, ciertamente sería fácil de controlar. La corrupción y la búsqueda de ganancias privadas son ambas consecuencia de una información imperfecta, y ambas pueden ocurrir tanto en el sector público como en el privado. (p.23)

Aunque el público (ciudadano) se preocupa por la eficiencia de las operaciones gubernamentales, este público reconoce que el monitoreo de los funcionarios públicos es poco estricto, por su naturaleza, y si bien no puede ejercer un control directo -dada su limitada capacidad de monitoreo- exige y logra muchas veces que se impongan una variedad de restricciones a los funcionarios públicos; a su vez, estas limitaciones, por mejor intencionadas que puedan ser, generan un costo, pues ellas pueden a veces interferir en la eficiencia y la eficacia con las cuales se producen los servicios gubernamentales. (Stiglitz, 2002)

En el contexto descrito, Stiglitz (2002) pone de manifiesto que se desarrolla una excesiva confianza en los procedimientos, que se traduce en las limitaciones impuestas por lo que se suponen son acciones de "control", con intentos por restringir la distracción de fondos públicos con fines privados en el sector público. "Pero al mismo tiempo que los procedimientos aumentan las probabilidades de que los fondos no se desvíen hacia usos privados, hacen más difícil que las instituciones públicas puedan responder rápidamente a circunstancias cambiantes" (Stiglitz, 2002, p.26). Lo cual a su vez se conjuga con el hecho que en el funcionario público promedio prevalece una mayor aversión al riesgo que en el de la actividad privada.

\footnotetext{
${ }^{9}$ Antes de su publicación, el documento fue presentado en el VI Congreso Internacional del Centro Latinoamericano de Administración para el Desarrollo (CLAD) sobre la Reforma del Estado y de la Administración Pública, celebrado en Buenos Aires, Argentina, del 5 al 9 de noviembre de 2001.
} 
Las limitaciones sobre la promoción y sobre la amenaza de ser despedido significan que el empleo público es, efectivamente, menos riesgoso que el empleo privado y, por lo tanto, serán los individuos con aversión al riesgo los que más se mostrarán atraídos por el empleo en el sector público (...). Si ocurre un error [en el sector público], si se observa una señal negativa, ningún individuo en particular puede ser culpado, en la medida en que se han seguido todos los procedimientos. (Stiglitz, 2002, p.27)

Esta última aseveración de Stiglitz abre una importante línea de investigación que conduce a una hipótesis que no está dentro del alcance de la presente investigación: al ser el directivo público promedio más averso al riesgo, se debe esperar que sea más propenso a cumplir acríticamente el excesivo celo controlista de la contraloría, por consiguiente, menos inclinado a innovar y modernizar la gestión pública.

Teniendo como soporte a diversos textos de administración de recursos humanos, se puede sintetizar en la Figura 1 el entorno que caracteriza la toma de decisión del directivo público, en el cual su percepción tiene un importante rol.

Figura 1. El entorno de toma de decisión del directivo público

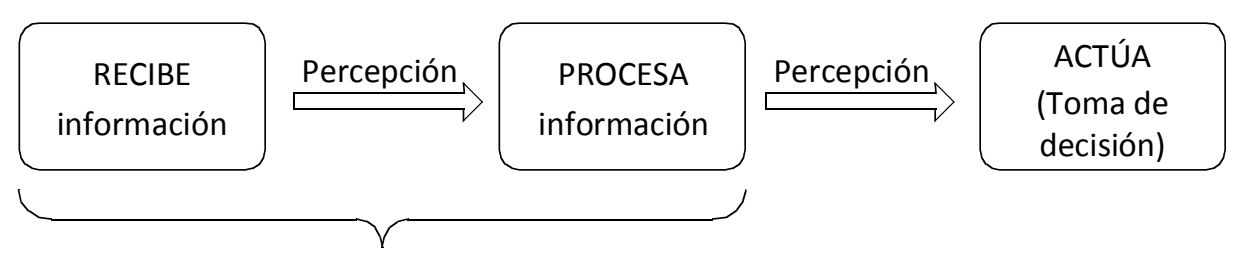

Para él (ella), no toda información es igualmente importante.

De las perspectivas de la teoría de campo de Lewin y la de la disonancia cognitiva ${ }^{10}$, Chiavenato (2007) concluye que la conducta de las personas se apoya más en sus percepciones personales y subjetivas que en hechos objetivos y concretos que existan en la realidad. "No es la realidad lo que cuenta, sino la manera personal e individual de visualizarla e interpretarla" (Chiavenato, 2007, pp. 46-47).

En base a esas dos teorías, citando a Thompson y Van Houten ${ }^{11}$, Chiavenato (2007, p.47) afirma que surgen tres enfoques para el estudio de la conducta de las personas:

\footnotetext{
${ }^{10}$ Teoría de campo de Lewin, en Lewin, Kurt, Principles of topological psychology, Nueva York, McGraw-Hill, 1936; Teoría de la disonancia cognitiva, en Festinger, Leon, A theory of cognitive dissonance, Stanford, Stanford Univeristy Press, 1957; ambos citados por Chiavenato (2007).

${ }^{11}$ En Thompson, James D. y Van Houten, Donald D., As ciências do comportamento: uma interpretação, São Paulo, Atlas, 1975, p. 30.
} 
1. La persona como un ser transaccional, que no solo recibe insumos del ambiente y reacciona a ellos, sino que también asume una posición proactiva, al anticiparse y muchas veces al provocar modificaciones en su ambiente.

2. La persona con un comportamiento dirigido hacia un objetivo, es decir que la persona es capaz de tener objetivos o aspiraciones y de hacer esfuerzos para alcanzarlos.

3. La persona como un modelo de sistema abierto, dirigido a objetivos, interdependiente con el medio físico y social, activamente involucrada en transacciones con ese medio en la medida en que persigue sus objetivos (...). Resulta importante conocer las percepciones de las personas y cómo estas elaboran una especie de sistema de filtros mediante los cuales conciben su realidad ambiental. [Subrayado propio]

De esa naturaleza compleja de la persona, se desprende que la conducta de las personas dentro de la organización también es compleja, y depende: de factores propios del individuo (internos), que corresponden a las características de su personalidad, capacidad de aprendizaje, motivación, percepción del ambiente interno y externo, actitudes, emociones, valores, etc.; y de factores ajenos a él (externos), que conciernen al ambiente, a las características organizacionales, a las recompensas y sanciones, factores sociales, políticos, cohesión grupal existente, entre otros (Chiavenato, 2007).

En la Figura 1 se verifica que el último eslabón en el entorno de la toma de decisión del directivo público es la propia toma de decisión, la cual tiene su correspondiente desarrollo teórico.

En el prólogo del libro de Bonome (2009), Wenceslao J. González manifiesta que uno de los rasgos centrales de la Teoría de la Decisión -entendida así también por Herbert Simon ${ }^{12}$, es su carácter "transversal", que ofrece una reflexión que abarca contenidos de un conjunto de disciplinas que se interesan por los agentes humanos en cuanto seres racionales que han de decidir entre varias opciones posibles. En esa amplia conceptuación, queda claro que también está comprendida la toma de decisiones del directivo de una universidad pública en el proceso de gestión de inversiones que, entre otros variados factores, toma en cuenta lo que hacen o dejan de hacer con respecto a dicho proceso los agentes contralores.

En el análisis que Bonome (2009) hace de Simon respecto de la toma de decisiones -que es entendida como una tarea a realizar por un agente dentro de una situación determinada-, indica que él resalta los siguientes factores que la caracteriza:

\footnotetext{
12 Herbert Alexander Simon, Premio Nobel de Economía en 1978, por su investigación pionera en el proceso de toma de decisiones dentro de las organizaciones económicas.
} 
1) los niveles de aspiración; 2) las expectativas que nos formamos sobre la base de esos niveles; 3) la atención puesta en los aspectos realmente relevantes de una situación; 4) el conocimiento que tenemos acerca del asunto a tratar, y 5) la complejidad del caso. (Bonome, 2009, p.76)

En el abanico complejo que implican esos factores, en el referido texto de Bonome (2009), se manifiesta que fruto del énfasis de Simon en el estudio de los procesos de decisión, se reconoce la racionalidad procesual o de procedimiento, según la cual hay una distinción entre el mundo real y la percepción que el agente tiene de ese mundo, la cual a su vez depende de sus características y circunstancias como sujeto. Además, se afirma que la realidad muestra que quienes toman decisiones son susceptibles de estar influidos por la formulación del problema, en cuanto que da forma a la percepción que se tendrá de las alternativas de elección.

Para el estudio del comportamiento económico de los agentes individuales, Bonome (2009) menciona que Simon propone tener en cuenta diversos acontecimientos de tipo histórico que rodean y conforman el entorno en el que se toman las decisiones. "Para trazar esos contornos variables, ve imprescindible incluir los cambios que continuamente se dan en las leyes, en el conocimiento, en las creencias, percepciones, valores e identificaciones de los agentes económicos respecto de sus grupos" (Bonome, 2009, p.62).

Sobre el papel que desempeña el estímulo en la toma de decisión del individuo, Simon reconoce que cuando un problema se presenta con un estímulo complejo, una persona percibe en él lo que está preparado para percibir; y cuanto más complejo o ambiguo es el estímulo, en mayor medida la percepción estará determinada por lo que está ya "dentro" del individuo y menos por lo que está "dentro" del estímulo (Bonome, 2009).

Para el pensamiento de Simon referido a la elección racional del agente económico, entiende que este busca, en principio, satisfacer sus necesidades y deseos, en lugar de enredarse en cálculos probabilísticos que le permitan elegir la mejor alternativa; por otra parte, refleja su condición humana de índole psicológica: que la racionalidad humana de los agentes está limitada por su propia percepción de la realidad y por su capacidad de cálculos de costo beneficio de la decisión a tomar (Bonome, 2009).

Por su parte, Salgado (2011) analiza el mecanismo de toma de decisiones para el caso particular de una empresa de transporte público en la Ciudad de México. En su contenido, se desarrolla elementos de perspectiva teórica, así como de una corroboración empírica, que conciernen a la toma de decisiones en los niveles de dirección. Así, indica que "la percepción es uno de los factores involucrados más relevantes y supone la interacción de los siguientes aspectos: la experiencia, la intuición, la percepción selectiva, el pensamiento, los filtros mentales, las creencias, las expectativas y las necesidades, entre otros" (Salgado, 2011, p.156). 
El mencionado documento hace referencia a que en el mundo contemporáneo, en el contexto empresarial, se ha instaurado en distinto grado el fenómeno de la globalización, que implica la caída de ciertas barreras físicas y mentales, en la cual el cambio parece ser la única constante. En tal contexto, Guiltinan (citado en Salgado, 2011) es de la idea que los gerentes conviven con un ambiente caracterizado por el cambio vertiginoso, por la creciente competencia de alcance multinacional y por las modificaciones políticas y económicas, por consiguiente, requiriéndose de parte de ellos una rápida adaptación a las nuevas condiciones del medio.

Salgado (2011), luego de exponer y analizar diversos planteamientos teóricos de investigadores sobre la materia, como Robbins (2009), Morris (2001), Manucci (2004), Seymour (1995) y García (1998), asevera que:

(...) podemos afirmar que la percepción se establece a través de todos aquellos estímulos o eventos del entorno que ingresan a nuestro cerebro a través de nuestros sentidos. Dichos eventos son analizados con el cedazo de nuestras creencias, pensamientos, modelos mentales, etc., para posteriormente emitir una respuesta. Podríamos pensar en un modelo de entrada, proceso y salida. Nuestro cerebro es una "máquina", en el sentido de un funcionamiento preciso y estructurado, que procesa la información (...). (pp. 161-162)

Citando y apoyándose en la definición de Stoner (1996), Salgado (2011) entiende que la "toma de decisiones" es el proceso para identificar y seleccionar un curso de acción para resolver un problema específico; por consiguiente, implica una interacción entre la intuición y el análisis, las interacciones sociales y la concepción del tiempo (experiencias del pasado, positivas y negativas), para elegir el "mejor" curso de acción para resolver una situación dada. En este contexto, los objetivos que se plantean los directivos para el futuro se basan, en parte, en experiencias del pasado.

El resultado de la investigación aplicada por Salgado (2011) al caso particular de una empresa de transporte público en la Ciudad de México, le permite inferir lo siguiente:

De acuerdo a lo que nos dicen los directivos y la teoría, son elementos importantes para la percepción: la intuición, la experiencia, la percepción selectiva, el pensamiento, los filtros mentales, las creencias, las expectativas, las necesidades, los conocimientos, la información histórica y las circunstancias. (p.170)

\section{ANTECEDENTES Y OBJETIVOS DE LA INVESTIGACIÓN}

El tema de la presente investigación no tiene antecedentes similares en el país ni en América Latina y el Caribe. Se examinaron documentos que son los más próximos posibles 
al referido tema, y que conciernen al Sistema Nacional de Control y la Contraloría General de la República (CGR) que, a su vez, es el órgano rector de dicho sistema; los cuales se presentan en este apartado.

En publicación emitida por la CGR ${ }^{13}$ (2014b), se propone ayudar a las autoridades de las entidades públicas a que tengan claro aspectos básicos y relevantes del control interno, tales como concepto, objetivos, normativa, roles, importancia, componentes y principios del Sistema de Control Interno, entre otros; asimismo, busca que los funcionarios y servidores públicos vean al control interno como una herramienta de gestión, orientada a prevenir riesgos y promover la eficiencia, eficacia, transparencia y economía, así como resguardar los recursos del Estado y mitigar irregularidades o actos de corrupción (CGR, 2014b).

El documento reconoce que en el país, desde el año $2006^{14}$, se han realizado diversos esfuerzos, a través de la emisión de normas y de documentos técnicos y orientadores, para establecer al control interno como herramienta de gestión que fortalezca y beneficie a las entidades públicas respecto del cumplimiento de sus objetivos y metas; sin embargo, en base al informe emitido por la propia CGR para medir la percepción de las entidades con relación a la implementación del Sistema de Control Interno - año 2013, admite que el avance de las entidades públicas en esta materia aún es débil o incipiente (CGR, 2014b).

Ante esa situación y acatando el mandato legal de ser el órgano rector del Sistema Nacional de Control (Ley $N^{\circ}$ 27785), la CGR emite el documento "Marco conceptual del control interno", dirigido a las entidades públicas, respecto del cual indica que la CGR:

(...) ha definido una estrategia para el fortalecimiento, promoción y evaluación del control interno en las entidades del Estado; siendo uno de los primeros productos un documento que le brinde al funcionario y servidor público, de manera uniforme, los conceptos y alcances del control interno, los roles y responsabilidades, las pautas para su implementación y en donde se identifique los beneficios e importancia del mismo (CGR, 2014b, p.7).

El referido documento de la CGR desarrolla de manera más didáctica -haciendo mención a antecedentes del control interno, la relación de este con los sistemas administrativos y sistemas funcionales de las entidades públicas- los conceptos, los objetivos y los demás aspectos que determinan la naturaleza de control interno en el sector público, establecidos en el correspondiente marco normativo regido por la Ley de Control Interno de las Entidades del Estado y sus normas complementarias.

\footnotetext{
${ }^{13}$ Este documento ha sido elaborado con la colaboración del Programa Buen Gobierno y Reforma del Estado de la Cooperación Alemana al Desarrollo (GIZ).

${ }^{14}$ Año en que se dicta la Ley de Control Interno de las Entidades del Estado, Ley № 28716.
} 
El Control Interno al ser una herramienta de gestión debe ser implementado por las propias entidades del Estado. Por ello, corresponde al titular y a los funcionarios la implementación y el funcionamiento del control interno en sus procesos, actividades, recursos y operaciones, orientando su ejecución al cumplimiento de sus objetivos (...) existen otros actores externos que deben brindar orientaciones para el mejor desarrollo del control interno así como realizar la evaluación del mismo, como son la Contraloría General, los Órganos de Control Institucional y las Sociedades de Auditoría. (CGR, 2014b, p.26)

En el documento además se pone en relevancia que el control interno en las entidades del sector público, a diferencia de las organizaciones privadas, deben tomar en cuenta el logro de objetivos sociales o políticos, la utilización de los fondos públicos, la importancia del ciclo presupuestario y la complejidad de su funcionamiento (CGR, 2014b)

Para el caso de las entidades públicas, en el texto se define el Sistema de Control Interno (SCl) como el conjunto de elementos organizacionales (planeación, control de gestión, organización, evaluación de personal, normas y procedimientos, sistemas de información y comunicación) interrelacionados e interdependientes, que buscan sinergia y alcanzar los objetivos y políticas institucionales de manera armónica; y, es un proceso multidireccional, no es secuencial (CGR, 2014b, p.28). Se reconoce, además, que el control interno no puede ser estándar, sino que debe adecuarse a las características y necesidades que tengan las entidades públicas; pero, tratándose de un sistema, es importante contar con ciertos parámetros que faciliten un lenguaje común, y ello deriva en los siguientes cinco componentes del SCI: Ambiente de Control; Evaluación de Riesgo; Actividades de Control; Información y Comunicación; y Actividades de Supervisión (CGR, 2014b).

Sobre la base de un amplio desarrollo conceptual concordado con el mandato normativo del país, y tomando en cuenta experiencias de otros países que han avanzado en materia de control interno (Estados Unidos, Colombia, México, etc.) formula una metodología y un modelo para evaluar el nivel de madurez del $\mathrm{SCl}$ en el país. Si bien este modelo no es complejo, pues considera una escala de evaluación de 0 a $5^{15}$ para cada uno de los cinco componentes, así como para el nivel agregado, la dificultad para muchas entidades públicas -que lo reconoce el propio documento- es contar con entidades públicas lo suficientemente organizadas y con capacidad de generar y entregar una adecuad evidencia (información), la cual debe tener como características: ser suficiente, competente, relevante y pertinente (CGR, 2014b).

${ }^{15} 0$ = Inexistente; 1 = Inicial; 2 = Intermedio; 3 = Avanzado; 4 = Óptimo; y 5 = Mejora continua (CGR, 2014b, p.47). 
En otro texto de la CGR ${ }^{16}$ (2014a), se plantea por objetivo proporcionar información referida al grado de avance de la implementación de los componentes del Sistema de Control Interno ( $\mathrm{SCl}$ ) en el Estado, por nivel de gobierno y tipo de entidad; asimismo, indica que el análisis de los resultados de la Implementación del SCI fue obtenida con el respectivo formulario de evaluación aplicado a 638 entidades públicas que cuentan con Jefe de Órgano de Control Institucional (OCI), a nivel nacional, clasificadas por tipo de entidad (CGR, 2014a).

Expone el conjunto de definiciones, objetivos, alcance, marco normativo y competencia de la CGR respecto del control interno, que sirven de soporte y conciernen a la metodología de medición, que es expuesta con detalle para analizar el grado de implementación del control interno en las entidades públicas del Perú.

Para evaluar el funcionamiento del $\mathrm{SCl}$ en las entidades del Estado, en el referido texto, la CGR elaboró un instrumento para medir su grado de implementación, denominado "Índice de Implementación del Sistema de Control Interno" (en adelante IISCI); el cual está compuesto por las calificaciones de Componentes y de Subcomponentes de las normas del control interno, y toma valores entre 0 y 1 , donde un mayor valor representa una mejor implementación, con cuatro rangos de calificación (Muy bajo, de 0,00 a 0,24; Bajo de 0,25 a 0,49; Medio de 0,50 a 0,74; y Alto de 0,75 a 1,00); y está basado en la aplicación de un cuestionario de 293 preguntas con opciones cerradas (que obliga a marcar una de ellas), las cuales tuvieron una respuesta del 85,5\% de las entidades públicas concernidas (CGR, 2014a).

La información recopilada y procesada demuestra la debilidad del control interno en las entidades públicas, lo que las expone a mayores riesgos de corrupción, entre otros problemas. Así, el IISCI promedio general a nivel nacional es de 0,38, ubicado en el rango bajo; por tipo de entidad, las empresas nacionales, organismos autónomos y empresas municipales se encuentran en el rango medio, mientras que las instituciones públicas descentralizadas, proyectos de inversión, ministerios, poderes del Estado - rectores, órganos desconcentrados, universidades $(0,35)$, municipalidades distritales, gobiernos regionales, municipalidades provinciales, sociedades de beneficencias públicas y juntas liquidadoras, se ubican en el rango bajo; siendo, a nivel departamental, Lima la que posee el más alto valor $(0,43)(C G R, 2014 a)$.

Los bajos valores hallados por la CGR en el mencionado texto dejan pendientes respuestas a, por ejemplo, las siguientes interrogantes que conciernen a las entidades públicas del país: ¿qué factores están a la base de esos bajos valores?; ¿acaso predomina la negligencia en los funcionarios de las entidades públicas en la implementación del SCl?, ¿̇o

\footnotetext{
${ }^{16}$ Este documento da cuenta de que la medición ha sido efectuada al 31 de julio del 2013. Asimismo, que ha sido elaborado con la colaboración de GIZ.
} 
el $\mathrm{SCl}$ para una entidad pública promedio es engorroso y genera retrabajos que no es posible implementarlo adecuadamente?, ¿o falta empatía de parte del equipo técnico y directivo de los $\mathrm{OCl}$ con la posición del directivo de la entidad pública evaluada, que debe atender frondosas disposiciones normativas de la gestión pública, además de cumplir con el $\mathrm{SCl}$ ?, entre otras. Ello, sin dejar de mencionar que, a pesar de que el proceso de descentralización en el país tiene más de 15 años, la región (departamento) de Lima demuestra un mejor desempeño en el $\mathrm{SCl}$, a su vez como muy probable consecuencia de una mejor distribución del recurso humano calificado en gestión pública; así como de un favorable reparto en decisiones y recursos en muchos otros aspectos de la gestión pública y otros ámbitos del quehacer nacional.

En otro documento, Rozas (2013) plantea como pregunta base (principal) si el control público en el Perú es el adecuado y contribuye al real control de las entidades públicas y, como preguntas específicas, cuestiona de qué manera se da el impacto social en el control de los recursos públicos, en qué medida el control gubernamental permite una adecuada administración de los recursos públicos, y de qué manera las normas y regulaciones permiten un adecuado control gubernamental (Rozas, 2013).

Para corroborar su hipótesis, el autor plantea el análisis en calidad de variable independiente, "Control público / gubernamental", y de variable dependiente, "Impacto social"; cuyos contenidos y naturaleza están determinados por un cuestionario de ocho preguntas (con una escala de calificación de 1 a 5, donde este último valor expresa la mayor situación positiva). La encuesta mereció la respuesta de 148 agentes conformados por directores de auditoría interna u órganos de control institucional, socios y auditores de sociedades de auditoría, directores de planificación, gerentes y/o jefes de las direcciones generales de administración, contador general y/o jefe de la oficina de contabilidad; a los que se suman expertos en auditoría y auditores con experiencia en auditoría gubernamental (Rozas, 2013).

Entre los resultados del mencionado estudio, destacan los siguientes hechos (Rozas, 2013):

a) Un $49 \%$ de los encuestados considera que no es eficaz el control público para la adecuada administración y/o gestión de los recursos públicos y, medianamente eficaz, el $46 \%$.

b) Un $61 \%$ de los encuestados considera que, en cuanto a la capacidad sancionadora de la CGR en materia de responsabilidad administrativa funcional de los servidores públicos, se constituyen en juez y parte.

c) Un 49\% considera el control ejercido por el Sistema Nacional de Control (CGR, básicamente) como regular y un $32 \%$ como malo; que suman a $81 \%$ los entrevistados que consideran entre malo y regular el indicado rol, principalmente de la CGR. 
En base a los resultados obtenidos en la investigación, otra de las conclusiones relevantes del autor es que a pesar de los esfuerzos que se realizan por parte del Sistema Nacional de Control (conducido por la GCR) en el Perú, este sistema no solo no estaría desempeñando una labor efectiva de lucha contra la corrupción, sino que los casos más importantes de este tipo son descubiertos por los medios de comunicación antes que por los órganos del referido sistema; además, que las irregularidades o actos de corrupción que finalmente se descubren, no todos son investigados y de los que se investigan, no todos se sancionan (Rozas, 2013).

El citado estudio de Rozas (2013), si bien contribuye con un útil trabajo descriptivo indiciario sobre un tema muy poco estudiado, adolece de algunas debilidades metodológicas: i) emplea una muestra poco representativa para inferir conclusiones para todo el sector público del país; ii) cerca de la tercera parte de los que respondieron la encuesta fueron funcionarios de los órganos de control de las instituciones que tomó como muestra, con el riesgo de un posible sesgo en las respuestas en favor de la labor de los propios órganos de control; iii) con información proveniente solamente de encuestas de opinión, es insuficiente para corroborar sus hipótesis explicativas (del tipo causa-efecto). Los indicios hallados acerca de lo que perciben directivos, especialistas y otros agentes concernidos con el control interno en el sector público peruano, empero, permiten profundizar investigaciones sobre el tema.

En otra investigación, de Gamboa, Puente y Vera ${ }^{17}$ (2016), se indica que el control interno es responsabilidad de cada institución del Estado y que esta debe crear las condiciones para que el ejercicio de control se realice como un proceso integral. Para ello, se debe poner en relevancia los componentes del control interno: el ambiente de control, la evaluación de riesgos, las actividades de control, los sistemas de información y comunicación y el seguimiento. Añade que los organismos del sector público deben contribuir al cumplimiento de los siguientes objetivos: promover la eficiencia, eficacia y economía de las operaciones bajo principios éticos y de transparencia, garantizar la confiabilidad, integridad y oportunidad de la información, cumplir con las disposiciones legales y la normativa de la entidad, para lograr bienes y servicios de calidad. (Gamboa et al., 2016)

Se indica en el documento que la implementación del sistema de control interno es responsabilidad del representante legal de la entidad, así como de todas las personas que trabajan en ella. Es por ello que su reglamentación busca sensibilizar a los funcionarios públicos sobre la relevancia de sus competencias. (Gamboa et al., 2016)

La indicada investigación sostiene que el control interno es un medio para el alcance de objetivos, por tanto, su ejecución debe ser responsabilidad de cada uno de los miembros de

\footnotetext{
${ }^{17}$ Trabajo de investigación publicado en la Revista Publicando, que se edita en Ecuador.
} 
la entidad partiendo de la alta dirección, considerando ciertos principios como: la igualdad, moralidad, eficiencia, economía, celeridad, imparcialidad, publicidad y valoración de costos ambientales. Por otro lado, es fundamental diferenciar entre el control contable y el control interno administrativo: el primero está relacionado con el control de las actividades propias del proceso contable; en tanto el segundo está vinculado con la eficiencia de las operaciones. (Gamboa et al., 2016)

Se pone de manifiesto la relevancia del cumplimiento de muchas leyes y regulaciones para la adquisición de ingresos y ejecución de gastos públicos. Entre las varias leyes a ceñirse se encuentran la ley de presupuesto, ley general de contratación pública, ley sobre la administración y la gestión pública, ley de contabilidad, ley de derechos civiles y protección del medio ambiente, entre otras. Sin embargo, la eficiencia del control interno no es perfecto, debido a que su elaboración depende del juicio del ser humano, por ello sujeto a errores; en consecuencia, limitando el cumplimiento de los objetivos institucionales. (Gamboa et al., 2016)

El artículo concluye que el seguimiento continuo se debe aplicar en el desarrollo habitual de las actividades, las cuales permitirán realizar evaluaciones periódicas que contesten a la necesidad de identificar las fortalezas y debilidades de la entidad. Con ello, la autoridad competente definirá las acciones preventivas o correctivas que se encaminarán a solucionar los problemas evidenciados por el control interno. (Gamboa et al., 2016)

Por todo lo desarrollado en el mencionado artículo, se ratifica la importancia del control interno en el sector público como una medida de prevención para el adecuado cumplimiento de los objetivos de las instituciones públicas; consiguientemente, en la necesidad de profundizar en el análisis de su desempeño en sus distintas vertientes. El citado artículo no lo indica, pero un ámbito importante a investigar en esa enmarañada red de normas a cumplir en la relación control interno - directivo público - resultados, por ejemplo, es la percepción de los directivos de las instituciones públicas respecto del papel de los agentes contralores en el proceso relacional.

Además de los trabajos de investigación arriba citados, hay artículos publicados en diarios de Lima por ex directivos de instituciones públicas o especialistas en gestión púbica (Bravo $^{18}$, 2016; Castagnola ${ }^{19}$, 2016; Narrea ${ }^{20}$, 2017; y Bonifaz ${ }^{21}$, 2018), que dan cuenta de frustrantes experiencias con la CGR, que en apretada síntesis se podrían resumir en:

\footnotetext{
${ }^{18}$ En la fecha de publicación del artículo, el PhD Sergio Bravo Orellana tenía a su cargo el Instituto de Regulación y Finanzas de ESAN (FRI-ESAN).

${ }^{19}$ En la fecha de publicación de su artículo, ejercía el cargo de Presidente ejecutivo de Apoyo Consultoría.

${ }^{20}$ Suscribe el artículo en su condición de investigador de la Escuela de Gestión Pública de la Universidad del Pacífico.

${ }^{21}$ En la fecha de suscribir su artículo, consignaba su condición de Director de la Escuela de Gestión Pública de la Universidad del Pacífico.
} 
i) Funcionarios de la Contraloría con poca experiencia y conocimiento sobre la materia auditada de importantes intervenciones del sector público terminan haciendo errados hallazgos, que las paralizan, en perjuicio de sus potenciales beneficiarios: el pueblo.

ii) La Contraloría se está convirtiendo en uno de los principales problemas que contraviene la búsqueda de eficiencia y efectividad de la gestión pública; inclusive llega a castigar experiencias exitosas.

iii) Es necesario establecer y poner en práctica una línea divisoria clara entre lo que le corresponde hacer a los funcionarios públicos y lo que deben hacer los funcionarios y técnicos del sistema de control, para evitar que estos últimos invadan ámbitos con elevado riesgo de colisionar con el buen funcionamiento del Estado.

iv) Nuestro sistema de control peca de asfixiante formalismo en el control de la legalidad, atemoriza a funcionarios y hace incurrir al Estado y a los privados en innecesarios costos.

v) El fortalecimiento de la Contraloría y la demostración de su poder le ha conducido a colisionar con otros sistemas administrativos, que no solo afecta la gestión pública, sino también la gobernabilidad del país.

vi) Se cuestiona la idoneidad técnica y el excesivo poder con que cuenta la CGR para sancionar administrativamente al funcionario público.

vii)En importantes proyectos para el desarrollo del país, el accionar de la CGR es contraria al principio de discrecionalidad que tienen los funcionarios públicos; que debe ser ejercida para optar la decisión administrativa debidamente sustentada con el fin de garantizar la ejecución oportuna de proyectos.

Los antecedentes y la naturaleza del problema expuestos, que conciernen al tema de la presente investigación, condujeron a plantearse los siguientes objetivos:

Objetivo 1: En la gestión de inversiones de las universidades públicas del país, identificar la brecha entre lo que las normas vigentes establecen son las funciones esenciales de los agentes contralores, y lo que perciben los directivos universitarios es el desempeño de estos agentes.

Objetivo 2: Desde la percepción de los directivos de las universidades públicas del país directamente involucrados en la gestión de inversiones, saber si consideran que los agentes contralores cumplen un papel negativo o no en esa gestión de su institución.

Objetivo 3: Formular recomendaciones que coadyuven a mejorar la relación entre los agentes contralores y los directivos de las universidades públicas; con la consiguiente mejora de la gestión de inversiones en estas instituciones. 


\section{HIPÓTESIS Y OTROS ASPECTOS METODOLÓGICOS}

En la presente investigación, se planteó las siguientes dos hipótesis:

Hipótesis 1: En la gestión de inversiones de las universidades públicas del país, existe una inconveniente brecha entre lo que las normas vigentes establecen son las funciones esenciales de los agentes contralores, y lo que perciben los directivos universitarios es el desempeño de estos agentes.

Hipótesis 2: Desde la percepción de los directivos de las universidades públicas directamente involucrados en la gestión de inversiones, los agentes contralores cumplen un papel negativo en esa gestión.

Para la prueba de hipótesis, se empleó las variables cuyas respectivas definiciones conceptual y operacional se explican en la siguiente tabla.

TABLA 1. Definición conceptual y operacional de las variables

\begin{tabular}{|c|c|c|}
\hline Variable & Definición conceptual & Definición operacional \\
\hline $\begin{array}{l}\text { Brecha de } \\
\text { desempeño de los } \\
\text { agentes } \\
\text { contralores entre } \\
\text { lo normado y lo } \\
\text { percibido }\end{array}$ & $\begin{array}{l}\text { Corresponde a la diferencia entre lo normado } \\
\text { y percibido de los siguientes indicadores: } \\
\text { i)Lo que las normas vigentes del Sistema } \\
\text { Nacional de Control del país establecen son } \\
\text { las funciones esenciales de los agentes } \\
\text { contralores. } \\
\text { ii)Lo que perciben los directivos de las } \\
\text { universidades públicas del país directamente } \\
\text { involucrados en la gestión de inversiones, } \\
\text { respecto del desempeño de los agentes } \\
\text { contralores. }\end{array}$ & $\begin{array}{l}\text { Cuestionario con un conjunto de preguntas } \\
\text { basado en la norma vigente del Sistema Nacional } \\
\text { de Control, en que cada una de ellas se } \\
\text { presentan en forma de afirmaciones para medir } \\
\text { la reacción del encuestado (directivo de la } \\
\text { universidad pública), y considerando el } \\
\text { Escalamiento de Likert de cinco categorías. En } \\
\text { este, la categoría de mejor valor indica pleno } \\
\text { cumplimiento por parte de los agentes } \\
\text { contralores del mandato normativo, y el peor } \\
\text { valor refleja su total incumplimiento. }\end{array}$ \\
\hline $\begin{array}{l}\text { Papel negativo de } \\
\text { los agentes } \\
\text { contralores en la } \\
\text { gestión de } \\
\text { inversión }\end{array}$ & $\begin{array}{l}\text { En el proceso de gestión de inversiones de las } \\
\text { universidades públicas del país, actuación de } \\
\text { los agentes contralores que en el ejercicio de } \\
\text { sus funciones influyen negativamente en el } \\
\text { desempeño de los directivos de esas } \\
\text { universidades. }\end{array}$ & $\begin{array}{l}\text { Cuestionario con preguntas, en que cada una de } \\
\text { ellas se presentan en forma de afirmaciones para } \\
\text { medir la valoración del encuestado (directivo de } \\
\text { la universidad pública), teniendo en cuenta el } \\
\text { Escalamiento de Likert de cinco categorías; en el } \\
\text { cual, la de mayor valor expresa una influencia } \\
\text { absolutamente negativa, mientras que la del } \\
\text { menor valor indica que no existe ninguna } \\
\text { influencia negativa. }\end{array}$ \\
\hline
\end{tabular}

Para corroborar las mencionadas dos hipótesis, se siguió los pasos y aplicó los procedimientos metodológicos que se indican a continuación.

En cuanto a la identificación de la unidad de análisis, se consideró dos determinantes básicos: por un lado, el marco normativo que rige el proceso de gestión de inversiones en las universidades públicas; el cual tiene en cuenta que los aspectos fundamentales de la 
gestión pública están regidos por sistemas normativos que transversalmente regulan al sector público ${ }^{22}$, tales como los sistemas de planificación, de inversiones, de presupuesto, de compras, de tesorería, de contabilidad, de organización, de control, etc. En consecuencia, desde el punto de vista normativo, los diferentes procedimientos básicos que implican la gestión de una inversión en una universidad pública son esencialmente similares a los de otra universidad pública. El otro determinante fueron los funcionarios que toman decisiones en las áreas orgánicas de cada universidad pública directamente vinculadas con la gestión de inversiones.

La revisión de ese marco normativo permitió conocer también que existen normas y sistemas que rigen la organización y funciones de la entidad pública, y que tienen un carácter transversal al sector público. En tal contexto, se revisaron las normas de organización y funciones de cada universidad pública, para identificar las áreas orgánicas de la institución y sus consiguientes funcionarios concernidos con el proceso de gestión de inversiones de ella; esto es, las unidades de análisis.

Efectuada la revisión, análisis y síntesis del respectivo marco normativo del tema de investigación, asimismo, elaborado un diseño preliminar de la encuesta de opinión, se trabajó a modo de focus group en la Universidad Nacional de Ingeniería (UNI), entrevistas a los jefes o directores de las áreas orgánicas fundamentales en la gestión de inversión de esta institución, para: i) identificar a las áreas y funcionarios claves en la toma de decisión en la gestión de inversiones en las universidades públicas del país; y ii) corroborar la pertinencia del contenido y aplicación del cuestionario correspondiente a la encuesta de opinión, así como atender sus posibles mejoras.

Mediante el indicado proceso, el cuestionario de la encuesta de percepción de los directivos universitarios sobre el papel de los agentes contralores en la gestión de inversiones de sus instituciones, quedó estructurado en dos bloques de preguntas, en correspondencia con las dos variables identificadas a evaluar (ver Tabla 1), del siguiente modo:

- Preguntas sobre la "Brecha de desempeño de los agentes contralores entre lo normado y lo percibido". El cual a su vez tiene tres sub-bloques: el primero de 16 preguntas; el segundo, de 10 preguntas; y el tercero, también de 10.

\footnotetext{
22 En la parte normativa, se considera como entidades conformantes del sector público (o entidades públicas), a los siguientes: i) Poderes Legislativo, Ejecutivo y Judicial; ii) Ministerio Público, Jurado Nacional de Elecciones, Oficina Nacional de Procesos Electorales, Registro Nacional de Identificación y Estado Civil, Consejo Nacional de la Magistratura [ahora Junta Nacional de Justicia], Defensoría del Pueblo, Tribunal Constitucional, Contraloría General de la República y Superintendencia de Banca, Seguros y Administradoras Privadas de Fondos de Pensiones; iii) universidades públicas; iv) gobiernos regionales; v) gobiernos locales; y vi) organismos públicos de los niveles de gobierno regional y local.
} 
- Preguntas sobre el "Papel negativo o positivo de los agentes contralores en la gestión de inversión". Está constituido por dos sub-bloques: el primero, de 12 preguntas; y el segundo, de 12 preguntas.

\section{La Tabla 2 ilustra la estructura del mencionado cuestionario.}

TABLA 2. Estructura del Cuestionario de percepción de los directivos universitarios sobre los agentes contralores en la gestión de inversiones en las universidades públicas del Perú

Datos generales del encuestado (6 preguntas)

\section{Preguntas sobre la Brecha de desempeño de los agentes contralores entre lo normado y lo percibido}

Los tres bloques de preguntas tienen como propósito identificar, desde la percepción del directivo de la universidad pública, el grado de cumplimiento por parte de los agentes contralores del Órgano de Control Institucional (conocido también como Órgano de Control Interno) y/o la Contraloría General de la República, de los fundamentos esenciales del control normados en el país y que deben regir sus actuaciones.

P1. Por favor evalúe el nivel de cumplimiento de las normas esenciales que rigen el accionar de los agentes contralores en la universidad que usted trabaja, empleando la siguiente escala de calificación:

\begin{tabular}{cccccc}
\hline $\mathbf{0}$ & $\mathbf{1}$ & $\mathbf{2}$ & $\mathbf{3}$ & $\mathbf{4}$ & $\mathbf{5}$ \\
\hline No sabe & $\begin{array}{c}\text { Absoluta falta de } \\
\text { cumplimiento }\end{array}$ & $\begin{array}{c}\text { Mayormente lo } \\
\text { incumplen }\end{array}$ & $\begin{array}{c}\text { Cumplimiento } \\
\text { intermedio (a medias) }\end{array}$ & $\begin{array}{c}\text { Mayormente lo } \\
\text { cumplen }\end{array}$ & $\begin{array}{c}\text { Pleno } \\
\text { cumplimiento }\end{array}$ \\
\hline
\end{tabular}

(16 preguntas)

P2. Tomando en cuenta el accionar de los agentes contralores respecto a la universidad en que usted trabaja, por favor indique qué tan de acuerdo está con cada uno de los siguientes enunciados, empleando la siguiente escala de calificación:

\begin{tabular}{|c|c|c|c|c|c|}
\hline 0 & 1 & 2 & 3 & 4 & 5 \\
\hline No sabe & $\begin{array}{c}\text { En total } \\
\text { desacuerdo }\end{array}$ & $\begin{array}{c}\text { Mayormente en } \\
\text { desacuerdo }\end{array}$ & $\begin{array}{c}\text { Ni de acuerdo ni } \\
\text { desacuerdo }\end{array}$ & $\begin{array}{c}\text { Mayormente en } \\
\text { acuerdo }\end{array}$ & $\begin{array}{l}\text { Plenamente de } \\
\text { acuerdo }\end{array}$ \\
\hline
\end{tabular}

(10 preguntas)

P3. Teniendo en cuenta el accionar de los agentes contralores de la Contraloría y del sistema de control a cargo de ella, ahora en el ámbito del país, por favor indique qué tan de acuerdo está con cada uno de los siguientes enunciados, empleando la siguiente escala de calificación:

\begin{tabular}{cccccc}
\hline $\mathbf{0}$ & $\mathbf{1}$ & $\mathbf{2}$ & $\mathbf{3}$ & $\mathbf{4}$ & $\mathbf{5}$ \\
\hline No sabe & En total desacuerdo & $\begin{array}{c}\text { Mayormente en } \\
\text { desacuerdo }\end{array}$ & $\begin{array}{c}\text { Ni de acuerdo ni } \\
\text { desacuerdo }\end{array}$ & $\begin{array}{c}\text { Mayormente en } \\
\text { acuerdo }\end{array}$ & $\begin{array}{c}\text { Plenamente de } \\
\text { acuerdo }\end{array}$ \\
\hline
\end{tabular}

(10 preguntas)

\section{Preguntas sobre el Papel negativo o positivo de los agentes contralores en la gestión de inversión}

Este conjunto de preguntas tiene como objeto conocer, desde la percepción del directivo de la universidad pública, si consideran que la actuación de los agentes contralores influye negativa o positivamente en el desempeño de los directivos de la universidad pública en el proceso de gestión de inversiones de su institución.

P4. Tomando en cuenta el accionar de los agentes contralores respecto a la universidad en que usted trabaja, en el proceso de gestión de inversiones (desde su identificación, preinversión, inversión y puesta en marcha), por favor indique qué tan de acuerdo está con cada uno de los siguientes enunciados, empleando la siguiente escala de calificación 


\begin{tabular}{|c|c|c|c|c|c|}
\hline $\mathbf{0}$ & $\mathbf{1}$ & $\mathbf{2}$ & $\mathbf{3}$ & $\mathbf{4}$ & $\mathbf{5}$ \\
\hline No sabe & En total desacuerdo & $\begin{array}{c}\text { Mayormente en } \\
\text { desacuerdo }\end{array}$ & $\begin{array}{c}\text { Ni de acuerdo ni } \\
\text { desacuerdo }\end{array}$ & $\begin{array}{c}\text { Mayormente en } \\
\text { acuerdo }\end{array}$ & $\begin{array}{c}\text { Plenamente de } \\
\text { acuerdo }\end{array}$ \\
\hline
\end{tabular}

(12 preguntas)

P5. Teniendo en cuenta el accionar de los agentes contralores de la Contraloría y del sistema de control a cargo de ella, ahora en el ámbito del país, por favor indique qué tan de acuerdo está con cada uno de los siguientes enunciados, empleando la siguiente escala de calificación:

\begin{tabular}{cccccc}
\hline $\mathbf{0}$ & $\mathbf{1}$ & $\mathbf{2}$ & $\mathbf{3}$ & $\mathbf{4}$ & $\mathbf{5}$ \\
\hline No sabe & En total & $\begin{array}{c}\text { Mayormente } \\
\text { desacuerdo }\end{array}$ & $\begin{array}{c}\text { Ni de acuerdo ni } \\
\text { desacuerdo }\end{array}$ & $\begin{array}{c}\text { Mayormente en } \\
\text { acuerdo }\end{array}$ & $\begin{array}{c}\text { Plenamente de } \\
\text { acuerdo }\end{array}$ \\
\hline
\end{tabular}

(12 preguntas)

Sobre la base de la actividad de investigación exploratoria realizada en la UNI y las demás actividades mencionadas, se recopiló información de la Web de Transparencia de cada una de las universidades públicas referida a sus Reglamentos de Organización y Funciones (ROF), sus organigramas, sus funcionarios que participan en tomas de decisión del proceso de gestión de inversiones ${ }^{23}$, así como de sus e-mail y teléfonos de contacto.

Se aplicó la encuesta a una muestra de directivos de las 49 universidades públicas, registradas como tales por la Superintendencia Nacional de Educación Superior Universitaria (Sunedu) y que están operando ${ }^{24}$. En conjunto, a nivel nacional, la población de directivos concernidos en la gestión de inversiones de sus respectivas instituciones, ascendió a 490 .

Para esa población, se aplicó la siguiente fórmula para determinar el tamaño de la muestra ${ }^{25}$ :

$$
n=\frac{Z^{2} N p q}{(N-1) E^{2}+Z^{2} p q}
$$

\section{Donde:}

$n=$ tamaño de la muestra

$Z$ = límite de confianza para generalizar los resultados

$p q=$ campo de variabilidad, en la cual $p$ representa a los aciertos y $q$ a los errores

$E=$ error de estimación máximo aceptado

\footnotetext{
${ }^{23}$ Se consideró a los directivos que detentan esa posición por ser especialistas en el área orgánica que tienen a su cargo. En consecuencia, se excluye a rectores, vicerrectores y demás autoridades electas.

${ }^{24}$ Hasta 2019, dos universidades están creadas, pero no funcionan: la Universidad Autónoma Municipal de Los Olivos y la Universidad Nacional Tecnológica de San Juan de Lurigancho.

${ }^{25}$ El procedimiento seguido para determinar la muestra ha sido tomado de Torres (2000).
} 
Los valores considerados son:

$N=490$ directivos vinculados con la gestión de inversiones

$Z=1,65$ (para un nivel de confianza del 90,1\%)

$p=0,50$

$q=0,50$

$E=0,10$

Reemplazando valores, se tiene que el tamaño de muestra es 60 directivos.

\section{VERIFICACIÓN EMPÍRICA Y ANÁLISIS DE RESULTADOS}

\subsection{Validación de instrumentos}

El principal instrumento para la recopilación de información -como ya se ha indicado-ha sido la aplicación de un cuestionario a una muestra de directivos concernidos con la gestión de inversiones en sus correspondientes universidades. Para su elaboración se revisó en detalle el marco normativo básico del Sistema de Control en el Perú, determinado por: la Ley Orgánica del Sistema Nacional de Control y de la Contraloría General de la República, Ley $N^{\circ}$ 27785; la Ley № 30742, Ley de Fortalecimiento de la Contraloría General de la República y del Sistema Nacional de Control; la Ley $\mathrm{N}^{\circ} 28422$, que amplía las acciones de este sistema hacia temas de control ambiental, recursos naturales y el patrimonio cultural de la Nación; la Ley $\mathrm{N}^{\circ}$ 28557, mediante la cual se modifica la designación de los jefes de los órganos de auditoría interna del sistema nacional de control; la Ley de Control Interno de las Entidades del Estado, Ley $N^{\circ} 28716$; y la Ley $N^{\circ} 29622$, que modifica la Ley $\mathrm{N}^{\circ} 27785$ y amplía las facultades en el proceso para sancionar en materia de responsabilidad administrativa funcional.

El cuestionario fue sometido a verificación de su confiabilidad, mediante el coeficiente Alfa de Cronbach, aplicado a las respuestas de 20 directivos de la población bajo estudio, seleccionados aleatoriamente. La fórmula empleada es la siguiente:

$$
\alpha=\frac{K}{K-1}\left[1-\frac{\Sigma V_{i}}{V_{t}}\right]
$$

Donde:

$\alpha=$ Alfa de Cronbach

$K=$ Número de ítems (que corresponde al número de preguntas del cuestionario: 60 )

$V_{i}=$ Varianza de cada ítem (valor determinado en el i-ésimo ítem por los valores de sus 20 respuestas) 
$V_{t}=$ Varianza total (proviene de la varianza determinada por los siguientes 20 datos: la suma del valor de cada respuesta de las 60 preguntas contestadas por cada uno de los 20 directivos)

Se obtuvo el coeficiente Alfa de Cronbach 98,5\%, que según el criterio general sugerido por George y Mallery (2003, p.231), corresponde a una confiabilidad excelente. Por consiguiente, con ello quedó expedito su aplicación para la muestra probabilística.

\subsection{Pruebas empíricas de las hipótesis}

Determinado el tamaño de la muestra, así como la confiablidad del cuestionario, el siguiente paso consistió en gestionar la comunicación y respuestas del cuestionario por parte de los 60 directivos universitarios seleccionados para la muestra ${ }^{26}$, vinculados con la gestión de inversiones en sus respectivas instituciones. La encuesta implicó a directivos de 25 universidades públicas del país.

Seguidamente, se revisó la consistencia de las respuestas del cuestionario y se construyó la respectiva base de datos; luego se realizaron los correspondientes cálculos y sus análisis para la verificación empírica.

A continuación se presentan los procedimientos matemáticos y estadísticos seguidos para el cálculo de los valores de las variables:

$$
\begin{aligned}
& V 1=f(P 1, P 2, P 3) \\
& V 2=f(P 4, P 5)
\end{aligned}
$$

En las cuales,

V1: Valor de la Variable 1 de la Hipótesis Específica 1 ("Brecha de desempeño de los agentes contralores entre lo normado y lo percibido").

V2: Valor de la Variable 2 de la Hipótesis Específica 2 ("Papel negativo de los agentes contralores en la gestión de inversión").

P1: Bloque de preguntas referido a la evaluación del nivel de cumplimiento de las normas esenciales que rigen el accionar de los agentes contralores en la universidad que el directivo trabaja.

P2: Bloque de preguntas para evaluar el accionar de los agentes contralores respecto de la universidad en la que el directivo presta servicios.

\footnotetext{
${ }^{26}$ En algunos pocos casos se tuvo dificultad de comunicación con el directivo seleccionado. Ante ello, se procedió a seleccionar aleatoriamente a sus respectivos reemplazos.
} 
P3: Conjunto de preguntas referido a la evaluación del accionar de los agentes contralores de la Contraloría y del sistema de control a cargo de ella, en el ámbito del país, en lo que concierne a la brecha de desempeño del sistema de control entre lo normado y lo percibido.

P4: Conjunto de preguntas para evaluar el accionar de los agentes contralores respecto de la universidad en la que el directivo trabaja, en el proceso de gestión de inversiones (desde su identificación, preinversión, inversión y puesta en marcha).

P5: Bloque de preguntas referido a la evaluación del accionar de los agentes contralores de la Contraloría y del sistema de control a cargo de ella, en el ámbito del país, en cuanto al papel negativo o positivo de ellos en la gestión de inversión.

Siendo los datos generados por respuestas cualitativas con escala numérica, se procedió a aplicar el cuadro gradual de baremos ${ }^{27}$ para los mencionados bloques de preguntas $P 1$, $P 2, P 3, P 4$ y $P 5$.

En las siguientes tres tablas se desarrolla el procedimiento baremo para el bloque de preguntas $P 1$ del cuestionario.

TABLA 3. Determinación de valores mínimos y máximos de las preguntas del bloque P1

\begin{tabular}{cccc}
\hline $\begin{array}{c}\text { Valor de las } \\
\text { respuestas }\end{array}$ & $\begin{array}{c}\text { Número de } \\
\text { preguntas }\end{array}$ & $\begin{array}{c}\text { Valor } \\
\text { total }\end{array}$ & \\
\hline 1 & 16 & 16 & Mínimo \\
2 & 16 & 32 & \\
3 & 16 & 48 & \\
4 & 16 & 64 & Máximo \\
5 & 16 & 80 & \\
\hline
\end{tabular}

TABLA 4. Determinación de rangos para la evaluación de preguntas del bloque P1

\begin{tabular}{lccc}
\hline \multicolumn{1}{c}{ Nivel de cumplimiento } & Valor mínimo & Rango & Valor máximo \\
\hline Bajo nivel de cumplimiento & 16 & 21 & 37 \\
Cumplimiento medio & 38 & 20 & 58 \\
Alto nivel de cumplimiento & 59 & 21 & 80 \\
\hline
\end{tabular}

\footnotetext{
27 El procedimiento baremo fue sugerido y explicado por el profesor de estadística de la Facultad de Arquitectura, Urbanismo y Artes de la UNI, Mag. José Cruz Cabrera.

Dicho procedimiento fue concebido por el matemático François-Bertrand Barrême (1638-1703).
} 
TABLA 5. Nivel de cumplimiento de normas esenciales del sistema de control por partes de los agentes contralores, evaluado por directivos universitarios

\begin{tabular}{lccc}
\hline \multirow{2}{*}{ Nivel de cumplimiento } & Intervalo de & \multicolumn{2}{c}{ Directivos } \\
\cline { 3 - 4 } & valores & Número & Porcentaje \\
\hline Bajo nivel de cumplimiento & De 16 a 37 & 8 & $13.3 \%$ \\
Cumplimiento medio & De 38 a 58 & 40 & $66.7 \%$ \\
Alto nivel de cumplimiento & De 59 a 80 & 12 & $20.0 \%$ \\
\hline
\end{tabular}

Los resultados de esta última tabla permiten corroborar que para el $67 \%$ de los encuestados que respondieron el cuestionario, existe una medianía en el cumplimiento de las normas esenciales del sistema de control que rigen el accionar de los agentes contralores en la respectiva universidad que el directivo trabaja. Dicho con otras palabras, desde la percepción de dos tercios de directivos de la universidad pública vinculados con la gestión de inversiones de su institución, existe una brecha entre lo que la norma del sistema de control del país establece debe ser el accionar del agente contralor, respecto de lo que se ve como deficiente desempeño de los agentes contralores en el cumplimiento de sus propias normas.

Para las sucesivas aplicaciones de los baremos para los bloques de preguntas $P 2, P 3, P 4$ y $P 5$, así como para las variables $V 1$ y $V 2$, se sigue similares procedimientos de cálculos para la determinación de los valores mínimo y máximo de las preguntas, y la determinación de rangos para la evaluación de preguntas del correspondiente conjunto de preguntas.

Aplicando el procedimiento indicado para el bloque de preguntas $P 2$ del cuestionario, se tiene los siguientes resultados:

TABLA 6. Nivel de desempeño de los agentes contralores respecto de las normas básicas de gestión, evaluado por directivos universitarios

\begin{tabular}{|c|c|c|c|}
\hline \multirow{2}{*}{ Nivel de desempeño } & \multirow{2}{*}{$\begin{array}{l}\text { Intervalo de } \\
\text { valores }\end{array}$} & \multicolumn{2}{|c|}{ Directivos } \\
\hline & & Número & Porcentaje \\
\hline Bajo desempeño & De 10 a 23 & 10 & $16.4 \%$ \\
\hline Desempeño medio & De 24 a 36 & 39 & $63.9 \%$ \\
\hline \multirow[t]{2}{*}{ Desempeño satisfactorio } & De 37 a 50 & 12 & $19.7 \%$ \\
\hline & & & $100.0 \%$ \\
\hline Respondieron "No sabe" & & 1 & \\
\hline
\end{tabular}

La Tabla 6 resume la sensación que tienen los directivos de las universidades públicas vinculados con la gestión de inversiones de sus respectivas instituciones, con relación a la 
siguiente brecha normativa: teniendo en cuenta las normas que rigen los aspectos esenciales de la gestión de inversión, si los agentes contralores se ajustan a ellas, o tienen un desempeño que se aleja de lo que deberían ser sus niveles óptimos. Para el $64 \%$ de los encuestados, los agentes contralores, al actuar, expresan un conocimiento mediocre de los fundamentos normativos que rigen la gestión de las universidades públicas del país.

A continuación, se expone los resultados de la aplicación de baremo al bloque de preguntas $P 3$ del cuestionario:

TABLA 7. Desempeño de los agentes contralores del sistema de control, a nivel nacional, evaluado por directivos universitarios

\begin{tabular}{lccc}
\hline \multirow{2}{*}{ Nivel de desempeño } & Intervalo de & \multicolumn{2}{c}{ Directivos } \\
\cline { 3 - 4 } & valores & Número & Porcentaje \\
\hline Bajo desempeño & De 10 a 23 & 8 & $13.3 \%$ \\
Desempeño medio & De 24 a 36 & 33 & $55.0 \%$ \\
Desempeño satisfactorio & De 37 a 50 & 19 & $31.7 \%$ \\
\hline Respondieron “No sabe" & & & $100.0 \%$ \\
\hline
\end{tabular}

Esta tabla permite conocer la percepción que tienen los directivos universitarios encuestados respecto del desempeño de los agentes contralores de la Contraloría General de la República -principalmente-, a nivel nacional, considerando lo que debería ser la actuación de dichos agentes según lo normado, y lo que los directivos perciben al respecto. Así, para el 55\% de los encuestados, el desempeño de los agentes contralores a nivel nacional en el mencionado tema es de nivel medio, mientras para cerca de un tercio es satisfactorio.

La tabla que se presenta a continuación expresa el resultado del procedimiento baremo para el bloque de preguntas $P 4$ del cuestionario.

TABLA 8. Evaluación del accionar de los agentes contralores en la gestión de inversiones, realizada por directivos universitarios

\begin{tabular}{lccc}
\hline \multirow{2}{*}{ Nivel de perturbación } & Intervalo de & \multicolumn{2}{c}{ Directivos } \\
\cline { 3 - 4 } & valores & Número & Porcentaje \\
\hline Baja perturbación a la gestión & De 12 a 27 & 2 & $3.3 \%$ \\
Mediana perturbación a la gestión & De 28 a 44 & 42 & $70.0 \%$ \\
Alta perturbación a la gestión & De 45 a 60 & 16 & $26.7 \%$ \\
\hline \multicolumn{1}{c}{ Respondieron "No sabe" } & & 2 & $100.0 \%$ \\
\hline
\end{tabular}


La Tabla 8 expresa que para el $70 \%$ de los directivos universitarios encuestados, el accionar de los agentes contralores en el proceso de gestión de inversiones (desde su identificación, preinversión, inversión y puesta en marcha) en su respectiva universidad, es de mediana perturbación a esa gestión; mientras que un $27 \%$ considera que los agentes contralores se desempeñan con una alta perturbación al referido proceso de inversión.

Los resultados para el proceso baremo para el bloque de preguntas $P 5$ se muestran seguidamente.

TABLA 9. Evaluación del accionar de los agentes contralores del sistema de control, a nivel nacional, realizada por directivos universitarios

\begin{tabular}{lccc}
\hline \multirow{2}{*}{ Nivel de perturbación } & Intervalo de & \multicolumn{2}{c}{ Directivos } \\
\cline { 3 - 4 } & valores & Número & Porcentaje \\
\hline Baja perturbación a la gestión & De 12 a 27 & 1 & $1.6 \%$ \\
Mediana perturbación a la gestión & De 28 a 44 & 38 & $62.3 \%$ \\
Alta perturbación a la gestión & De 45 a 60 & 22 & $36.1 \%$ \\
\hline \multicolumn{1}{c}{} & & & $100.0 \%$ \\
\hline Respondieron “No sabe" & & 1 & \\
\hline
\end{tabular}

Esta última tabla evidencia que la percepción predominante de los directivos universitarios encuestados es que los agentes contralores en la gestión pública en el país no son buenas: el $98 \%$ considera que su papel es entre mediana y altamente perturbadora; el $62 \%$ lo considera medianamente perturbadora y el $36 \%$ altamente perturbadora.

A continuación, se presentan los resultados de aplicar baremo para el conjunto de preguntas que conforman la variable $V 1$, que concierne a la primera hipótesis de investigación; esto es, comprende las preguntas de las variables $P 1, P 2$ y $P 3$.

TABLA 10. Brecha de desempeño de los agentes contralores entre lo normado y lo percibido, evaluado por directivos universitarios

\begin{tabular}{lccc}
\hline \multirow{2}{*}{ Nivel de cumplimiento } & Intervalo de & \multicolumn{2}{c}{ Directivos } \\
\cline { 3 - 4 } & valores & Número & Porcentaje \\
\hline Bajo nivel de cumplimiento & De 36 a 83 & 4 & $6.7 \%$ \\
Cumplimiento medio & De 84 a 132 & 48 & $80.0 \%$ \\
Alto nivel de cumplimiento & De 133 a 180 & 8 & $13.3 \%$ \\
\hline \multicolumn{1}{c}{} & & & $100.0 \%$ \\
\hline Respondieron "No sabe" & & 2 & \\
\hline
\end{tabular}


La Tabla 10 expresa que, desde la percepción de los directivos de la universidad pública encuestado -concernidos directamente con la gestión de inversiones de su institución-, hay una medianía en el grado de cumplimiento por parte de los agentes contralores del Órgano de Control Institucional (conocido también como Órgano de Control Interno) y de la Contraloría General de la República, de los fundamentos esenciales del control normados en el país y que deben regir sus actuaciones. Para un $80 \%$ de los encuestados existe una brecha entre lo que debería ser la función de los agentes contralores y su mediocre desempeño; para el $7 \%$, la brecha es mucho mayor; mientras que solamente para el $13 \%$ no existiría la mencionada brecha.

Con estos resultados se confirma la primera hipótesis planteada por la presente investigación: "En la gestión de inversiones de las universidades públicas del país, existe una inconveniente brecha entre lo que las normas vigentes establecen son las funciones esenciales de los agentes contralores, y lo que perciben los directivos universitarios es el desempeño de estos agentes".

De modo similar para la primera variable, a continuación se presenta los resultados del proceso baremo para la variable $V 2$, conformada por los grupos de preguntas $P 4$ y $P 5$.

TABLA 11. Papel negativo o positivo de los agentes contralores en la gestión pública, evaluado por directivos universitarios

\begin{tabular}{lccc}
\hline \multirow{2}{*}{ Nivel de perturbación } & Intervalo de & \multicolumn{2}{c}{ Directivos } \\
\cline { 3 - 4 } & valores & Número & Porcentaje \\
\hline Baja perturbación a la gestión & De 24 a 55 & 0 & $0.0 \%$ \\
Mediana perturbación a la gestión & De 56 a 88 & 42 & $70.0 \%$ \\
Alta perturbación a la gestión & De 89 a 120 & 18 & $30.0 \%$ \\
\hline
\end{tabular}

Respondieron "No sabe"

2

Los resultados de esta última tabla indican que, desde la percepción de los directivos de la universidad pública encuestados, los agentes contralores del Órgano de Control Institucional y la Contraloría General de la República, tienen el siguiente papel: medianamente negativo para el $70 \%$; y que tienen una influencia altamente negativa para el $30 \%$.

Con estos resultados -que con consistentes con los hallados para los bloques de preguntas P4 y $P 5$ - se confirma la segunda hipótesis de la investigación: "Desde la percepción de los directivos de las universidades públicas directamente involucrados en la gestión de inversiones, los agentes contralores cumplen un papel negativo en esa gestión". 


\section{CONCLUSIONES}

- J. Stiglitz permite conocer el riesgo de que excesivos controles en las actividades del sector público resultan finalmente ser contraproducentes. La investigación patrocinada por el BID para América Latina y el Caribe reconoce que existen instituciones que no realizan auditoría de desempeño, debido a la falta de personal calificado en ellas. La CGR admite que el avance de las entidades públicas para establecer al control interno como herramienta de gestión que las fortalezca y beneficie respecto del cumplimiento de sus objetivos y metas, aún es débil o incipiente. La encuesta de la tesis de Rozas (2013) evidencia una desfavorable percepción de directivos del sector público y especialistas en auditoría, respecto del sistema de control en el país. Existen diversos testimonios expresados mediante artículos periodísticos por ex directivos públicos y expertos en gestión pública que critican el papel de intimidación implícita y paralizante de la CGR.

- La revisión de la literatura sobre entidades superiores de fiscalización (tipo la CGR en el Perú y entidades análogas en otros países), no evidencia que a nivel de América Latina y el Caribe se hayan realizado investigaciones que expliquen la naturaleza interna de esas instituciones, para conocer qué perfiles de profesionales están presentes entre sus integrantes, con qué nivel de experiencia y conocimiento cuentan respecto de las funciones de los cargos que ellos fiscalizan, cuáles son sus principales motivaciones en el ejercicio de sus funciones, cómo se relacionan con los directivos a quienes supervisan, entre otros asuntos de una evaluación hacia el interior de esas entidades fiscalizadoras. Este conocimiento daría luces sobre temas relevantes para mejorar el sistema de control en el sector público.

En suma, en lo que concierne al país, la revisión de los antecedentes sobre el tema de investigación da cuenta de hechos y opiniones que indican deficiencias en la gestión del control en las entidades públicas, que no les permite que sus intervenciones sean suficiente, competente, relevante y pertinente.

- En la relación directivo gestor y agente contralor, la percepción y la toma de decisión son dos aspectos de capital importancia. Al respecto, existe el correspondiente soporte teórico, pero se requiere de mayor atención por parte de la administración pública y la academia, tanto para conocer la naturaleza de esa relación, la percepción y toma de decisión de los involucrados, como sus implicancias, en una perspectiva de mejora de esa relación para beneficio de la comunidad.

- Con los resultados hallados en la encuesta y expuestos en las respectivas tablas, se puede concluir:

- Se verifica la Hipótesis 1: "En la gestión de inversiones de las universidades públicas del país, existe una inconveniente brecha entre lo que las normas 
vigentes establecen son las funciones esenciales de los agentes contralores, y lo que perciben los directivos universitarios es el desempeño de estos agentes". Para un $80 \%$ de los encuestados existe una brecha de incumplimiento medio; para el $7 \%$, la brecha de incumplimiento es mucho mayor; mientras que solamente para el $13 \%$ no existiría la mencionada brecha.

- Se corrobora la Hipótesis 2: "Desde la percepción de los directivos de las universidades públicas directamente involucrados en la gestión de inversiones, los agentes contralores cumplen un papel negativo en esa gestión". Según esa percepción, los agentes contralores del Órgano de Control Institucional y la Contraloría General de la República, tienen el siguiente papel: medianamente negativo para el 70\%; y que tienen una influencia altamente negativa para el $30 \%$.

- El 42\% de los directivos a quienes se les aplicó el cuestionario tiene como tiempo de servicio en el cargo encuestado dos años o menos. Lo cual revela baja permanencia en el puesto de parte importante del cuerpo directivo vinculado con la gestión de inversiones de la respectiva universidad; además, que implica mayores esfuerzos y tiempos institucionales para que cada corto tiempo los nuevos directivos conozcan las funciones específicas del nuevo puesto que están asumiendo, asimismo, empleen tiempo y actitud para establecer relaciones con otros directivos de la institución con los que tiene que coordinar para llevar adelante la gestión en su nuevo puesto. Y estas dificultades debilitan la eficacia, eficiencia y oportunidad de las acciones directivas y operativas de la entidad universitaria.

- Existen hechos conexos a la aplicación de la encuesta que acontecieron en varios casos que -sin ser una proporción mayoritaria-, deben ser tenidos en cuenta:

- Se evidencia una práctica excesivamente burocrática ${ }^{28}$ en algunos funcionarios. No obstante que a cerca del $25 \%$ de los encuestados se les había informado por escrito y verbalmente que las respuestas del cuestionario serían procesadas anónimamente, sin indicar sus identidades ni la institución en la que trabajan, asimismo, que sus respuestas correspondían a su particular percepción sobre las materias que se estaba encuestando, en unos casos persistían en tener previamente la autorización de la autoridad universitaria, en otros, la de sus superiores.

- En la mayoría de las universidades públicas su Portal de Transparencia está incompleto o desactualizado en lo que respecta a la información de sus principales oficinas, los nombres de sus titulares (o encargados), de sus números telefónicos y correos electrónicos de contacto. Por sus antecedentes, esas deficiencias parecen ser independientes de las dificultades de la Covid-19.

${ }^{28}$ Entendida como administración ineficiente a causa del papeleo, la rigidez y las formalidades superfluas. 
Todo lo mencionado -que incluye los resultados de la presente investigación- permite concluir que se debe evaluar con profundidad y prontitud un nuevo marco normativo y una nueva cultura de gestión del sistema de control en el país, acompañado de una revisión técnica rigurosa de la composición del recurso humano contralor y su desempeño.

\section{RECOMENDACIONES}

- Un tema que se considera pertinente mencionarlo a la luz de los resultados hallados y las expresiones directas de algunos encuestados, es revisar con detenimiento los incentivos que se otorgan a los agentes contralores, que dependen directamente de la CGR y de los órganos de control institucional. Concordante con lo manifestado por algunos directivos encuestados, así como en algunos artículos de diarios de circulación nacional, lo que ellos observan es que se premia los hallazgos -mejor si se orientan a "castigos" severos- o similares que identifican en sus labores cotidianas los agentes contralores, determinando así una suerte de incentivo perverso en el ejercicio de sus funciones, que afectaría el desempeño de los funcionarios públicos y perjudicaría la buena operatividad del sector público.

Se dice incentivo perverso, porque los hallazgos de los agentes contralores corresponderían a asuntos predominantemente superfluos, pero con suficiente efecto de intimidación y de inhibir acciones o iniciativas que osen salirse de los parámetros de esas exigencias superfluas. Para el directivo comprendido en este contexto restrictivo y punitivo, lo más sencillo es no hacer nada contrario a lo que dispone el órgano de control ni la CGR, para evitarse problemas. Bajo estas condiciones, en la administración pública prevalecería la mediocridad y la burocracia superflua, parsimoniosa e insensible a los requerimientos de una mejor atención a la comunidad.

- Otro asunto está referido a inquietudes expresadas por algunos directivos en entrevistas telefónicas sostenidas con ellos, las cuales se pueden resumir en las siguientes: de todos los agentes contralores del sistema de control, ¿qué porcentaje de ellos han desempeñado funciones de conducción y ejecución en un organismo público?; y de los que han tenido esa experiencia, ¿por cuánto tiempo lo han hecho, enfrentando los sinnúmeros de dificultades normativas y operativas de la administración pública?

Las preguntas son pertinentes, porque según los entrevistados se evidencia falta de empatía de los agentes contralores respecto de las funciones y responsabilidades que debe asumir el directivo público, para atender diversas exigencias de superiores, de los usuarios de los servicios que proporciona la entidad, de las distintas entidades del Estado que rigen la gestión pública, así como las que plantean los propios agentes contralores. Añaden que en sus diversas experiencias directivas en el sector público no conocen casos de felicitaciones u otro tipo de reconocimiento gratificante que hayan expresado los agentes contralores o la CGR. 
- Los dos parágrafos precedentes, así como las conclusiones de este trabajo, sugieren que debe realizarse un estudio sobre la composición del recurso humano que dirige y realiza actividades de control en el sector público, que entre otros aspectos demanda conocer la cultura de trabajo que rige sus acciones. Un presupuesto anualmente creciente que le asigna el país a la CGR ${ }^{29}$ (que para el año 2020 es S/ 624,6 millones), merece que se le exija como contrapartida a este órgano que cumpla cabalmente el papel que la ley le ordena en beneficio de la gestión pública y los usuarios finales de esta, y no enfocarse en un papel predominantemente punitivo y de intimidación, que inhibe a la fuerza innovadora y proactiva en el sector público.

\section{AGRADECIMIENTO}

Se contó con la asistencia de los estudiantes de la FIEECS Loribeth C. Prudencio Rodríguez y Piero Giovanni M. Berrospi Vega. En la revisión y orientación estadística del diseño de la encuesta y tratamiento de sus resultados, se contó con la colaboración del docente principal de la Facultad de Arquitectura, Urbanismo y Artes de la UNI, estadístico y Mag. José Cruz Cabrera.

\section{REFERENCIAS}

Bonifaz, José Luis (19 de octubre de 2018). Contraloría: ¿̇hasta cuándo la cacería? El Comercio, p.22.

Bonome, María G. (2009). La racionalidad en la toma de decisiones: Análisis de la Teoría de la Decisión de Herbert A. Simon. La Coruña, España: Netbiblo, S. L.

Bravo Orellana, Sergio (25 de julio de 2016). Cuando Contraloría castiga el éxito: El caso del Proyecto Perú. Gestión. Recuperado de http://blogs.gestion.pe/inversioneinfraestructura/2016/07/cuandocontraloria-castiga-el-exito-el-caso-del-proyecto-peru.html

Castagnola, Gianfranco (26 de agosto de 2016). Contraloría en cuestión. El Comercio, p.30.

Chiavenato, I. (2007). Administración de recursos humanos: el capital humano de las organizaciones (Octava edición). McGraw-Hill.

Contraloría General de la República. (2014a). Medición de la implementación del Sistema de Control Interno del Estado [2013]. Recuperado de https://apps.contraloria.gob.pe/wcm/control_interno/ documentos/Publicaciones/Medicion_Implementacion_SCI_Estado_2013.pdf

Contraloría General de la República. (2014b). Marco conceptual del control interno. Recuperado de https:// apps.contraloria.gob.pe/wcm/control_interno/documentos/Publicaciones/

Marco_Conceptual_Control_Interno_CGR.pdf

${ }^{29}$ Según la información del Portal de Transparencia Económica del Ministerio de Economía y Finanzas, la CGR ha ejecutado los siguientes gastos anuales: S/ 530 millones en el 2017, S/ 572 millones en el 2018, y S/ 681 millones en el 2019. 
Gamboa Poveda, Jinsop, Puente Tituaña, Silvia Paulina, y Vera Franco, Piedad Ysidora (2016). Importancia del control interno en el sector público. Revista Publicando, 3(8), 487-502. Recuperado de: https:// dialnet.unirioja.es/buscar/ documentos?querysDismax.DOCUMENTAL_TODO=Importancia+del+control+interno+en+el+sector $+p$ $\%$ C3\%BAblico

George, Darren, \& Mallery, Paul. (2003). SPSS for Windows step by step: A simple guide and reference. 11.0 update (4thed.). Boston: Allyn \& Bacon.

Hernández Sampieri, Roberto, Fernández Collado, Carlos, y Baptista Lucio, María del Pilar (2014). Metodología de la investigación (6a edición). México D.F., México: McGraw-Hill.

Jarquin, María J., Molina, Evelyn, y Roseth Benjamín. (2018). Auditoría de desempeño para una mejor gestión pública en América Latina y el Caribe. Banco Interamericano de Desarrollo. Recuperado de https://publications.iadb.org/es/auditoria-de-desempeno-para-una-mejor-gestion-publica-enamerica-latina-y-el-caribe

Narrea, Omar (31 de mayo de 2017). La cultura del descontrol. El Comercio, p.30.

Rozas Flores, Alan Errol (2013). El impacto social del control público en el Perú (tesis para grado académico de Doctor en Ciencias Contables y Empresariales). Universidad Nacional Mayor de San Marcos, Lima, Perú.

Salgado Guzmán, Oscar Diego (Julio-diciembre de 2011). El papel de la percepción en la toma de decisiones de la alta dirección. Iberofórum, Revista de Ciencias Sociales de la Universidad Iberoamericana. Año VI, No. 12, pp. 156-173.

Stiglitz, Joseph (2002, febrero). Mejorando la eficiencia y la capacidad de respuesta del sector público: lecciones de la experiencia reciente. Revista del CLAD Reforma y Democracia, (22), pp. 7-68.

Torres Bardales, Colonibol. 2000. Orientaciones Básicas de Metodología de la Investigación Científica (Séptima edición). Lima, Perú. Libros y Publicaciones.

Los artículos publicados por IECOS pueden ser compartidos a través de la licencia Creative Commons: CC BY 4.0 Perú. Permisos lejos de este alcance pueden ser consultados a través del correo revistas@uni.edu.pe. 